EthnoAnthropoZoom

159.942.6:323.22-057.87(497.7)

323.269.3-057.87(497.7)

\author{
Ana Blazheva, (North Macedonia) \\ Institute of Social Sciences and Humanities - Skopje \\ e-mail: ana.gjorik@gmail.com
}

\title{
AFFECTIVE POLITICS OF THE “AUTONOMOUS ZONE”: FROM MELANCHOLIA TO EMPOWERED POLITICAL ACTION
}

\begin{abstract}
The paper examines the political potential of melancholia as part of the affective politics of the "Autonomous Zone," an action implemented by the Student movement "Student Plenum" in 2015 in Macedonia. The main focus is on the affective potential of the "Autonomous zone" as a temporary, embodied, and enacted political practice. In the beginning, the focus is on the psychoanalytic concept of melancholy and its social aspect. Then, the social aspect of the affectivity of melancholy is presented as a marginalized position. The example used here refers to the melancholic and marginalized status of the students in Macedonian society before the student movement.

Further, the theoretical framework draws from the contemporary interdisciplinary approach towards embodied and enacted social participation in a shared world. It is a phenomenological perspective towards social action that incorporates intersubjectivity, intercorporeality, and interaffectivity. This approach is then used as the ground for analysis of the affective politics inspired by the work of Silvia Federici and her claim that reproductive work and sphere can serve as a potential for political imagination and anticapitalist social transformation.

The research and analysis are implemented on the specific part of the Students movement in Macedonia "Student Plenum" from 2015, embodied and enacted through the occupation of the University named "Autonomous Zone." The Autonomous zone lasted for two weeks, during which the students organized the life in and the space of the Philosophical and Philological Faculties on the University campus of "St. Cyril and Methodius" in Skopje. The analysis follows embodied and enacted experiences of affects, space, intimacy, dialogue, solidarity, and responsibility as central aspects of the affective politics, which they used as political tools and personal transformation capacity. The analysis shows that students' affective experiences during the occupation were the core aspect of the transformation of their melancholic experience and marginalized social position.
\end{abstract}

Keywords: affective, politics, melancholy, marginalized, intersubjectivity 


\section{Melancholy of the marginalized}

Psychoanalytic discourses on melancholy explain the unconscious dynamics that create and perpetuate the melancholic experience. In this section of the paper, I discuss the psychoanalytic theories on melancholy by Freud, Klein, and Kristeva and then use emotion's racial and cultural politics to explain the sociality of melancholy and its dynamics in the social field.

Freud considers melancholy as a pathological process of mourning, differing from non-pathological mourning. We mourn the loss of a loved object. It could be a person, idea, etc. In mourning, the energy invested in the loved object is gradually withdrawn from the object and referred to other objects. In melancholy, the energy from the cathexis ${ }^{1}$ It is not referred to as another object but becomes identified with the ego itself. Therefore, "In the process of mourning, the world becomes empty while in melancholy it happens with the ego" (Freud 1917, 246). This identification of the ego with the loss enables the phenomenology of melancholia to settle (Freud 1917).

Julia Kristeva provides insight into the melancholic position that traps all the potentials for overcoming the absence of the other and keeps the subject closed in its bubble (Kristeva 1989). Through the processes of identification and introjection, irreparable emptiness is created in the place of the lost object. Unfortunately, this interpretation of the psychodynamic processes of loss and its impact on the self does not leave much room for intervention or exit from the isolation, which is the effect of melancholy.

However, Melanie Klein's studies on early development open space for intervention and exit. Her approach gives access to the complexity and interconnectedness of psychodynamic processes. According to her approach, nothing can be considered outside of the complex relations and different experiences that result in the permanent co-creation of the child with the environment. Thus, my reading of Klein's work is in line with the intersubjective aspect of emotionality. Furthermore, Klein points to the possibilities for overcoming the depressive states by creating representations and an inner world in which children reflect and transform the dynamics of the environment (Klein 1935). According to her approach, nothing should be viewed outside the complex relationships and experiences resulting from continuous co-creation of the child and the environment. Therefore, my reading of Kline's theory in that sense is in line with the intersubjective and the enactment approaches of emotionality.

Klein, like Freud, describes melancholy as a loss of an object or a similar situation with the same meaning, which leads to internalization of the lost object into the ego. If introjection fails, a subsequent pattern identified as the "loss of the loved object" is created. The relationship with the mother and other people who take care of the child allows the internalization of these experiences (Klein 1935). Pleasant experiences that strengthen the feelings of love and trust reduce fear; help the child to overcome depression and the sense of loss (mourning). They use external reality to check the internal one. When children feel loved, which is experienced through the pleasure and comfort in relationships with other people, these experiences reinforce their belief in their goodness and

1 In psychoanalysis, cathexis is defined as the process of investment of mental or emotional energy in a person, object, or idea. 
the kindness of others and strengthen their hope. This also reduces the fear of their disintegration and internal destruction (Klein 1935).

Klein explains a more complex psychological dynamic that gives perspective and possibility for overcoming the melancholic position. And here, it is important to note that this possibility is grounded in children's experiences with different adults, thus on the various quality of relations they experience. Therefore, I argue that transformation of the melancholic experience is possible throughout the links we create in the social field, instead of as individualistic and isolated achievement and result of the internal dynamics and potentials. And this potential for overcoming the melancholic position will be explored further in the text.

En Cheng uses psychoanalysis in her analysis of understanding American racial culture through the concept of racial melancholy. She explains the American racial culture through the dynamic of rejection and internalization of the "other" (Cheng 2000). Cheng explains how racial melancholy can be used as a concept that can help understand the mourning and the loss as a symptom and a dynamic process with transformative potential for political imagination. Melancholy of the marginalized offers a theoretical framework for analysis of the constitutive role of mourning in the process of subjectivization. I will argue that the transformation of the mourning and the exit from the injury can open the political potential of the marginalized subjectivity and collectives.

Sara Ahmed analysis the cultural politics of emotion, explaining the phenomenology of emotional experience as part of a complex process of social change. She argues towards understanding emotions, not as internal psychological processes but complex processes that always incorporate the social aspect through emotion as a cultural practice. In phenomenology, emotions are associated with intentionality - always directed "towards something." For Sara Ahmed, this means that they are associated with a confident attitude towards the world to understand the world. Emotions appear in relations shaped by previous contact histories with different social and cultural practices (Ahmed 2004). She considers emotions to be circulating among the objects, surfaces, and bodies that they shape. I use her approach towards the sociality of emotions as embodied and embedded in the context. According to Ahmed, emotions are never only subjective experiences; they manifest themselves through the body, shaping its surfaces and boundaries. She uses her analysis of pain to explain that even in pain, besides the subjective experience that cannot be shared, there is an intersubjective space shaped by the pain. The intersubjective aspect doesn't mean that we feel the pain of the other but that being present with/for the other, our relation is shaped through the current emotion. It means that emotions are never encapsulated within one's body but are already part of our relationships with each other and with the world.

New interdisciplinary approaches of emotionality in terms of embodiment and enactment are suggesting that we "live in a shared world understood in terms of participatory and broader collective sense-making processes manifested in dynamic forms of intercorporeality, collective body memory, artifacts, etc." (Durt, Fuchs \& Tewes, 2017, 1). Thus they propose an investigation of dimensions of empathy, interaffectivity, identifications of oneself with others, and hermeneutical understanding of the thoughts of others. (Durt, Fuchs \& Tewes, 2017, 1). The authors describe the shared world as "constituted by 
intersubjective understanding that discloses things in the shared significance they have for the members of a culture" (Durt, Fuchs \& Tewes, 2017, 2).

Along these lines, I use this approach in analyzing the embodiment and enactment of the student's experiences during the occupation of the University named "Autonomous zone." My goal with this paper is to understand how the shared space and political vision are related to the intersubjective and interaffective aspects of students' experiences and how these experiences constitute affective politics that transformed students' melancholic experience and marginalized social position towards empowered political action. This will be the supporting argument of the paper that melancholy bears transformative potential for empowered political action.

The theoretical framework for affective politics as an essential aspect of political imagination I offer is also inspired by Silvia Federici, a Marxist feminist theorist and activist. Her analysis has shown that reproductive work (women's work in homes that enable reproduction and sustainability of life - taking care of the food and health for the children, men, and elders) was fundamental for sustaining capitalism. Thus she suggests that reproductive work should be basic for the political imagination and of social change. My take is that the affective aspect of reproductive work is one of the core aspects that could be used as a concept for political imagination and social transformation.

In this paper, I use data from the ethnographic research conducted during 2015 on the student movement in Macedonia. The study was undertaken to write my doctoral thesis, "Melancholy and Politics: The Melancholy of the Marginalized Subject and Communities in the Republic of Macedonia." The research methods used for the research were: desk research on the student movement - Student plenum, observations during the Autonomous zone, 20 in-depth interviews with ten students, participants in the Student plenum. This paper will use the information from the desk research, field, and reflexive notes from the observations and transcripts from the interviews with students.

The main question I will address in the paper is how affective politics of the Autonomous zone can transform the melancholy and the marginalized position into empowered political action. First, I will give a short introduction to the marginalized positions of students before the movement arose, then a short timeframe of the activities before the occupation as essential background for enabling the affective politics of the Autonomous zone.

\section{Marginalized position of students in Macedonia}

In this part of the text, I give contextual information of the students' position in terms of their social status and student organization. Desk research showed that there is little data and analysis on students' status and organization. However, the available data offers insight into the challenges of student organizations and their overall social status.

According to the documentation of the university "St. Cyril and Methodius" (UKIM), "The students, as the prominent participants in the educational process, participate in all forms of management through the Student Parliament of UKIM. The Stu- 
dent Parliament is an organization of student representatives representing their interests, demands, and proposals. Representatives of student parliaments represent the Student Parliament of the University at the separate faculties. The students are described in the bodies of management of the faculties (Dean's Administration and Teaching-Scientific Council), in the bodies of UKIM (University Senate, Rector's Board), and all commissions of UKIM. Also, they are represented in the commissions for self-evaluation and evaluation of the faculties and the University "(UKIM website).

According to the legal framework, the Student Parliament and its representatives have the exclusive right to participate in the decision-making processes. However, experience and research data show that the Student Parliament does not reflect and advocate the needs, demands, and attitudes of the students (Poposka 2010). In addition, students face censorship of free thought through censorship at oratorical evenings organized at the Faculty of Law, the closing of the student radio, lack of a student newspaper or magazine, etc. (Poposka 2010).

Along these lines, the Republic of Macedonia does not have rich experience of independent student organization and student movements. The first independent student organization began in 2009 with the Independent Student Movement "Free Index." The movement invoke the legacy of the student movements from the 1968 and advocate for free education, student self-organization, the autonomy of universities and emancipatory education system ${ }^{2}$. With the slogan "Be realistic, demand the impossible," they attempted to articulate dissatisfaction among students. This slogan was later also used by the Student Plenum as part of the protests and the "Autonomous Zone." Therefore, it represents the continuity of thought and the idea of student organization from 68 to the present and its political legacy.

The marginalization of students is also related to the student standard: poor educational conditions, lack of access to academic literature, poor conditions in student dormitories, small scholarships and credits, non-functioning of the student organization and ombudsman, disrespect of ethical code, etc. Several articles depicted student standards by presenting students in dormitories with broken lifts, dark corridors, substandard conditions for hygiene, rooms with moldy walls, poor nutrition, etc. Here is an excerpt from a student's statement that talks about the requirements in student dorms and student standard 3 :

Most foods are available in September and October. Then they start to disappear. We have only chicken steaks with a limited amount declared on the dining hall wall - each student could have only $200 \mathrm{~g}$ of steak. We wait in line for $40 \mathrm{~min}$ utes for a piece of steak and a serving of French fries. The fries are eaten with a spoon because there are not enough forks. Last year in the buffet, there were

2 Independent Student Movement "Free Index." Statute. Available at: http://slobodenindeks. blogspot.mk/p/blog-page_160.html Accessed on: 14.10.2018

3 Portal "Aktuelno 24" Students from dormitory Goce Delchev with more than half-million euro annually, the Ministry doesn't know how this money is spent (30th September 2014) http://aktuelno24.mk/foto-studentite-od-gotse-delchev-tezhat-polovina-milion-evra-godishnoministerstvoto-ne-znae-kako-se-troshat-ovie-pari. 
juices, but not this year. Hot water and heating are also rare. There are no fire extinguishers on any of the floors. Cats and dogs are at home in the corridors. On each floor, there is one toilet and shower without doors. It is not convenient, but we must use them because there is no other option. In each block, there are two elevators; one of them most probably doesn't work. The corridors are pure horror; the lights do not work, or broken flashing lights all the time. When it rains, it rains inside, and there are problems with the electrical installation.

These images of horror speak of ignorance and humiliation towards students on behalf of the authorities. Apart from substandard and inhuman conditions, students' research data also contain statements confirming their marginalized social status.

BR: So yes, I can say that students face devaluation of the status in the last fifteen-twenty years. And especially with this government has its role in downgrading the position and the level of students. Students were apathetic, extremely apathetic, indifferent to their future, or seeing its future only outside this state and society or through the political party engagement and employment.

The melancholic position of the students is reflected in their apathy, confusion, and confinement faced with uncertainty, unemployment, and lack of opportunities for self-realization.

KM... I had other plans, to find a job, to write my thesis but nothing happened, and I was pretty...I was depressed for a year. I did not want people to see ... My brother is an economics student, and he is not here (pause); he is not interested, he is subsumed in complete apathy, it is not that he does not care; he thinks he cannot change anything.... It's easy to get into apathy, and it's too easy, you talk about melancholy, it's the most widespread thing in our life (pause). I know countless people close to me, innovative, staring at stars, practicing astronomy as a hobby (pause) some stare at the stars, some do drugs, some in excessive oblivion. Because this is precisely what is expected, because you hit walls all the time about everything, there are a million constraints. Every day you see how powerless you are and slowly accept it.

The position students support the melancholy position have during their studies, the treatment in the institution, and the professors. Their expectations and needs to be motivated and the pursuit of high achievement does not meet the conditions that enable it.

BP:...IthinkIcamewithexpectationstobeencouragedtogivemybestanddevelop something that was previously suppressed, my potentials that were not created, Iexpected to have space to express myself to bechallenged, but it didn't happen..., and the people around me and the professors and the institution as such and the relations in it were so conservative, unexpectedly conservative! Unexpected.

And: What was your emotional response?

BP: It hurt me! In a way ... and ... I was either withdrawn or aggressive, I was passive-aggressive. I was insolent and acted out with resentment. I used 
to start a discussion that was not related to the lecture content only because I needed to discuss issues; I needed to hear questions from other students; I needed discussions on relevant matters, not just for coffee and the like. I needed it, and sometimes I expressed it wrongly, with hatred. Sometimes I reacted aggressively with hostility towards the people around me, which I considered robots, less toward the professors, but still, I had an unfriendly attitude. Or I was withdrawn as I was not interested in anything, felt like I did not come here for this, or was down... Once I accepted that the situation is as it is, I told myself, ok, I need the diploma, just do whatever it takes, and continued to go through the years as an indifferent robot.

Melancholic experiences speak of disappointed expectations, unfulfilled personal potentials, interests, and needs that are treated as irrelevant and irrelevant. This makes them feel unhappy, depressed, and in a subordinate position.

MN .... the professor's attitude towards the students, that is, the teachers do not respect you as a colleague or future collaborator, but see you as subordinate, you're just there to take an exam, pass nothing else. And I think my rebellion reflected in my studies, I was the only student to ask for more, to oppose teachers, and it was hard for me.

Translated into psychoanalytic discourse, the marginalized position of the students is the result of the loss of their place and importance in society, the identification of their potential, and the lack of recognition and respect. Students mourn for being excluded, subjugated, for the loss of self-confidence and self-worth.

\section{The establishment of the "Autonomous zone."}

The "Autonomous zone" was established as part of the political strategy of the "Student plenum," a student movement that was formed in 2014 as a reaction to the announcement of the new changes in the Law for Higher Education. The changes were perceived by most of the students and professors to be threatening the sovereignty of the University by imposing external evaluation of knowledge through the introduction of the system of external testing later named "state exam." The first student protest was held on 17th November 2014 and gained broad public support. The second protest was born on the 10th December 2014 march by more than 10000 people. Students filed a request to the Government of the Republic of Macedonia with argumentation against the changes of the Law on Higher Education.

However, the Parliament accepted the changes of the Law, and soon it was placed into force. As a result, the students announced the occupation of the University. The "Autonomous Zone" occupation was scheduled for 11th February 2015 at the Faculty of Philosophy and Philology at the "St. Cyril and Methodius" in Skopje. The "Autonomous zone" was prepared by informing the students from all the faculties and boycotting the lectures days before its official opening.

The occupation was chosen as a political tool that served different goals. First, to claim the University's autonomy, and second, to put pressure on the government to withdraw the changes of the Law. Aside from its political and strategic aspect, as a political 
gesture, it also served as the empowering process for students' repositioning in society. Finally, it was an act to reclaim the political space and experiment with the embedded and enacted vision of freedom and democracy.

On the first day of the "Autonomous Zone," students organized their life at the Faculty building. They organized the safety rules and patrols, food and drink corners, arts and entertainment spaces, and the "bedrooms" lecture rooms transformed into sleeping areas. Open call for donations for basic needs such as food, blankets, hygiene, etc., was announced. The cultural and educational program was also prepared each day and announced on the Facebook page of the Student plenum. Approximately fifty students were spending the nights in the classrooms adapted as bedrooms. Fifty to a hundred students were always in the atrium as the main socializing space and event place. After a few days of successful occupation on the Faculty of Philosophy and Philology, the occupation had spread to other Faculties - Faculty of Electrical Engineering and Information Technology, Pedagogical academy, Architecture, Agriculture, Art Academy.

On the fourteenth day of the "Autonomous Zone," on 24th February 2015, the second meeting of the working group with the stakeholders - students, professors, and representatives from the Ministry-was held. All parties agreed on working and drafting a new Law. The students and professors perceived this as a victory and celebrated with the party announcing the ending of the "Autonomous zone" and the occupation of the University. Two days later, the "Autonomous Zone" ended.

\section{Phenomenology and the affective politics of the "Autonomous Zone."}

This part of the text depicts the affective experience, the organization of life, and the lived embodied experience in terms of intimacy, intersubjectivity, dialogue, solidarity, and responsibility. Students' affective experiences during the "Autonomous Zone" provide an overview of the transformed melancholy position in a strengthened and articulated political action.

The affective phenomenology could be summarized to cover the wide range of emotional experiences and atmosphere. These include joy, excitement, love, admiration, empathy, insecurity, fear, anxiety, anger, and rage. Students spoke about the constant excitement they felt, the easiness to approach and be with others. Powerful political affects also constitute their lived experience. Students share their experiences that they thought triumphant, revolutionary, and as winners. They often used words like energy, magic, etc., to describe the atmosphere in the "Autonomous Zone."

KM: Joy, at first it was a joy! .... I could get to know about literally 20 - 30 people a day, it was a pleasure for me! It was sooo good! .... at some point, I felt a sense of (pause) pride for myself, but I felt for other people .... great respect and great love and admiration. Because a few (pause) did so much! 
MN: I mean, all the time, it was a lot like adrenaline elevated me and when we went to the protests as well... Perhaps in an infantile way I felt so revolutionary (laughs)... but that was the desire, the feeling ...

MN: Mmm, the palette chronologically would have been like this (laughs): First - anger (laughs). First, it was not anger; it was like rage: "What do they do to us?" Yes, as injustice, after it grew into rage... And the moment when we were in front of the Rectorate, we waited for our colleagues to come out and the moment they came out and said that there would be a new law (laughs) means we started crying! (laughs) It was, I do not know, something unique! Since we all started to hug each other ...

These affects map the social and political transformation of the students' melancholic experience and marginalized position. It also offers interaffective perspective of the transformation. The transformation was a shared experience; not just an individually felt one. The power of the transformation can also be noted though the increased intensity of the affects. Psychodynamic and contextual elements can explain such intensity. The first one being the fast transformation that took place in a short time. From a position of being apathetic and isolated to the point of being exalted by joy and power. Such affective transformation could elevate the experience of emotions. The public reacted overwhelmingly supportive, and the fact that students had been in the focus of public interest and support could also influence the affective intensity. Finally, the novelty of the situation, the intensified exchange, the dynamics, and the scale with/on which the events took place influenced the emotional experiences to be amplified and more pronounced.

BR. Wow! Yes! There was adrenalin the whole time, and I was in a situation of constant excitement! There was excitement, too much excitement, I never experienced that much excitement, it was continuous...pretty simple there is excitement, and it carries you away; it is an engine, it is the energy.

These affective atmosphere set the framework of affective politics and was embedded in a specific material context - the space that was part of the transformation. Therefore, an essential aspect of the "Autonomous Zone" was its location and the space it occupied. What was before the institutional administrative place was transformed to be the place of most intense shared social, political, and intimate space. The transformation of the space reflected the intersubjective experiences; walls became the site for the articulation of the political demands and political vision, the air was filled with music also reflecting both the affective and the social and political perspectives. Students experienced the space differently as lecture rooms served as bedrooms, while the area was filled with their favorite music or creative workshops.

TP. Sincerely for me, it was beautiful, the moment of posters all over the place with messages of wisdom, to students' creativity, so it was terrific for me in that space, I felt fulfilled and realized that we do something meaningful! We developed our creativity, we developed our mind, we developed sharpness, critical 
thought, we developed our place literally, in which each of us has, as we say, a paintbrush topaintitscolor!Anditwassuchabeautifulmomentforme, honestly.

VL. Yes, it was to sleep at the Faculty! Sleeping there was the strangest experience in all of this... To cover yourself and to fall asleep, to wake in the morning and to be at the Faculty!

VR. That space was for four years you've entered with lowered head... because the professors are your small gods, the dean is your arch-enemy...and you go there to finish your part, go to the lecture, pack your bags and go home, the longings are there, but you can't do much...there is no one to listen to you...we all have separate lives....and now suddenly, in the room where you've had methodology lectures, you roll your blanket and you sleep there! And it is yours! There was freedom in the air!

MN. Yes, yes the music was the thing that relaxed us all since we were free to play whatever music we've wanted, or I could play some Albanian music, for everyone could listen to Albanian music, then we had classical music and many others, we had folklore and many different.

The organization and rearrangement of the space served the emerging needs, and political claims also reflected the new embodied and enacted students' position. Thus, students transformed the area, and their melancholic experience was also part of the transformation. They refer to this transformation in terms of empowerment.

LL. It empowers, it empowers, again, I think that the certainty we've created together, which is...I do not know, which signifies a merging point, which gives back in return with confidence, which has affected us all. I mean, as if I told you, we all somehow knew it was ok. ... Yes, we silently knew that we ... that we are not sorry, that this is not lost time, that for the first time we see what this time of our life means and what it is aimed at. Because you know, a crisis as young people we all had before at all levels, existential, professional, it stopped while we were there, there the problem was squeezed out...

The new and unique experience of organizing life through everyday activities while politically engaging for the University's autonomy embodied the University's new vision. This vision was both physically, socially, and emotionally lived during the occupation. Moreover, occupying the space, living and working in that space for students was a significant symbolic claim, a significant political determinant that they insisted on (students demanded the negotiations with the government's representatives and the Ministry to take place on the academic ground). With the occupation and reframing of the space, they expressed their rebellion, nor only the political pressure but also reimagined their political vision, their place in academia, and their participation at the University. 
VL: ... And the energy was extraordinary because we were accustomed to the Faculty in somehow a lot more institutional way. You go to lectures; you go to deal with administration, you go out, and you go home. Now you are coming, and all the people are here! You know that their home is here now! They will not go anywhere (smiling) that nobody will go anywhere; here we will all be, this is our home. It was strange (smiling)

Qualitatively different relations were developed with their professors more openly and immediately without the administrative boundaries as they had discussions and exchanges as fellow academic colleagues. Relations among students are the most crucial part of the intersubjective experiences during the occupation. This intersubjective aspect also has the transformative power of the melancholic experience and marginalized position.

The relations were established and developed in two parallel processes: the organization of life in the "Autonomous zone" and the political deliberation and dialogue as part of the plenum sessions. Both processes were equally crucial in the creation of the community. The first process was covering the aspects of relation through socialization, intimacy, and belonging, while the second process referred to the ideological and political aspects of the link. Therefore, I will address at first the organization of life and later on the political aspects of the deliberation and dialogue.

Shifting how students socialized is one of the aspects of intersubjective experience. Students shared experiences that instead of constantly being on mobile phones and the Internet, they could be together and play social games without being online. The life in this new community they've created brought new light and different affective value to the relations with their peers. They've enjoyed the immediate contact they've had and the exchange and closeness it enabled.

TA: ... but there was also a lot of laughter, so for example, about three o'clock when we had a plenary meeting, a hysteria of laughter started. We forgot to socialize without the technology, and now since the telephones were empty in the evening, we had to put them all on charging, the alcohol was forbidden, so we were there and hung out together and talk, without needing alcohol for relaxation, without a phone to turn the web on, communicating with each as in childhood when we played in front of a building.

BG. It was weird; I don't know how to describe it, it is an institution where before I submitted documents, where I did only official things as a student. And now the professors were sitting with us, we were drinking coffee, smoking, and feeding together, we were hanging out, and those contacts keep to exist, but in those moments, they happen fast, you can have an immediate conversation in their cabinet, you can discuss freely. So somehow, it brings the Faculty close to you ... 
Creating a community in which members are engaged in the reproductive aspects of everyday life gives a feminist dimension to the political action. It confirms the feminist claim that "the private is political" and not only that, but it also emphasizes the importance that the processes of the intimate, reproductive, "female" sphere are an inseparable part of creating a community in a political sense. A political act or community function necessarily involves emancipating gender, emotion, identity, and economy. In that sense, an essential component of the "Autonomous Zone" is non-exclusive but inclusive regarding any identity. Additionally, the "Autonomous Zone," although being the microcommunity, impacted emancipating economic processes, especially for the members of the community. This was reflected in how the settlement of basic needs was organized through a solidarity economy. Students recognized the power of the reproductive and intersubjective experiences and organized a lecture within the "Autonomous Zone's" program entitled "The Woman's Face of the Revolution" that addressed the feminist aspect of their community and society general.

BR: There was a feminine morphology! So there was no such mark and bearing element as in other movements, as we can see, for example. It was interesting; I think it was mentioned by Anna or Irena, where the private was opened to the public. Where public and private often intertwine.

Together with the reproductive aspect, another dimension of the intersubjective experience I explored with the students was intimacy. Students were referring to different parts of intimacy that they've experienced and changed during the occupation. They spoke about embodied experiences of sharing intimate space in the new environment and the change and developments of close relations with others. Students also referred to attitudes, as renegotiation and reframing of their attitudes towards sexuality, ethnicity, ideology as part of the intimate transformations resulting from the experiences during the occupation.

BG: In that autonomous zone, many romantic relationships were born and some old broken up, new sympathies, new attitudes were established. Something that you did not have before in intimate experiences. I think that at the moment, I understood the concept of intimacy a bit differently from before. Relations were developed with new people, in a different way, more open in which I felt free and all of it is shared within that community.

BR: And in the very intersubjective aspect, let's say, it was so..., I and the relationships that I had with some people there, for example, I noticed myself in different moments, where I want to be alone, but I am among others. So there was exciting magic! Since, most often, I want to be alone, I do not want to be with other people, and now I was alone; I was in constant dialogue with myself, but people surrounded me, and I was with them! It was like a new symbolic paradigm for me. Being with both yourself and others! This is when you experience yourself as an infinite cosmic picture that is constantly in some relationship with other celestial bodies and is continuously enriched with different symbols, to say so. It was an exciting sit- 
uation; it is a unique experience of my life ... I am overjoyed! Because I see some kind of humanization in myself in that process of communitarianism!

Responsibility was another aspect of the enacted experience significant for students in their everyday life in the "Autonomous Zone." They were taking responsibility for themselves, the energy, security, and space they claimed as occupied. And the responsibility was both enacted through the reproductive care for the life during the occupation and the negotiations process. These reproductive aspects of the organization during the occupation as an enacted aspect of the experience are directly related to their empowerment and dedication to democratic values and mainly their position, role, and participation at the University. Furthermore, their political mandate was enacted through the commitment towards the process of negotiation with the Government and the Ministry.

SB: We have to show that we honestly care about such things as autonomy the security, and life at the Faculty because it was very important; we slept and ate there. These are some things, I think, that made me feel like we are responsible for the autonomous zone with which we created (laughs), and so it was.

Students felt a particular pride for they have managed to demonstrate responsibility and constructiveness throughout the process, and they articulated it by creating a space in which they could freely express their criticism towards the educational system, but at the same time to contribute to the development and praxis of a new approach to how the education process might be. Responsibility is a dimension of democratic participation and governance but also an inevitable aspect of creating a community. Therefore, I argue that responsibility allows the feeling of belonging, solidarity, and care to develop. In this way, responsibility is related to the intersubjective experience in the sense of belonging, "being at home." And the sense of belonging is one of the basic foundations towards creating a new political community.

BP: I would separate the sense of responsibility that developed into the people involved. The feeling of "this is ours, we created it together "... "this is ours, and we take care of it" and we should find our place in it, and we should contribute ... that care and responsibility ... I saw them in many people, maybe not at all but in many people, I saw them and that pleased me, it was part of the thread that makes a community, and they are those feelings ... mutual care, sharing, giving, solidarity, blooming, blooming like in no other community or atmosphere I've seen previously. I do not know what exactly this was precisely what inspired people to be so open to others and to share so much and to connect, whether the same space that was ours or the Plenum as an idea... some combination did it and existed. Everything was ours, and everything was familiar and nobody acted through stereotypes, prejudice, no one rejected anything from others ... I felt it ... maybe I've caught such moments, at the end of the day I do not know, but I felt cooperation and sharing, responsibility, a sense of collective care and it was the most beautiful experience. 
LL: Yes, in relation to the Autonomous zone and holding of that space, besides the internal turmoil, I think we were very responsible. Without that...that, that creation of a new political community it is impossible without responsibility.

MN: Well, it was literally like a commune! We all were people about the same age and students, so we did not have anyone there telling us what to do, so it was literally like a commune; we were all free to do what we want, no one had to control us and tell us what we should not do, because we had a responsibility. After all, in some other situation, we might not be so obedient, but good at all, but in this case, we were; we kept the peace as something most sacred if someone violates it as if it were not one of us.

The feeling of communion is not only a matter of the political dimension. For some students, it represents a new intimate experience of being with others, without coercion and limitation, but meaningful and creating a sense of fulfillment.

Solidarity is another aspect of the intersubjective relation of care, expressed through the concrete act of support. Students considered solidarity one of the main principles of their movement and community and the primary support mechanism for their organization and functioning. They've spoken about the solidarity within the student plenum and the support they've been receiving from the citizens through donations, encouragements, protest joining, reliance on social networks, etc. It stretched the boundaries of their community, reaching and solidarizing with the broader societal movements. It extended the social boundaries through the inclusion of differences and otherness.

KM: Without solidarity, there is no freedom, since without solidarity, what you have is fear. But when someone is empathetic with you, you are not scared. And you can see and feel it.

BG: It was good that the Plenum expressed solidarity not only inside the community but also outside it; everything that is inside the community is not solidarity but mutual help for survival, it is not solidarity, but sharing food with low-income families showed that the community knows how to function with other communities as well.

One of the concrete examples of solidarity was manifested through public shaming and hate speech that occurred on the social networks of one of the LGBT students from the movement. Student plenum as the community and many students personally publicly spoke out in defense. This act of solidarity also expressed the inclusiveness of the activity being the first social movement to support LGBT people openly. Those principles are crucial for the cohesion of the student movement and contributed to the democratization of the public discourse. Moreover, such examples of solidarity are essential as personal experiences and individual empowerment. The quotation below can illustrate the empowering moment of solidarity for this particular student. 
VL: It was so lovely, all the energy and all the people! I don't know, when the attack from Republica happened against me, they tried to discredit me on sexuality grounds, to give the unclear image of my sexuality, I didn't expect such reaction from the people from the Plenum. They all came, one by one, people that I don't know and hug me, people that I thought were homophobic in a way (he laughs) hugged me, gave me support, saying nice words, I couldn't believe!

This case also leads to another more elaborated dimension of solidarity as a new boundary of the political. Willingness to take risks individually, onto oneself, one's own body is the expression of the basis of the community in a political sense.

LL: If I have to expose myself intimately, it is my foundation for the new society, only through this, only if we can speak less and practice it more. What does it mean to practice it? It means exposure, it means a risk that will translate your feeling and your attitude towards the other, for example, with migrants, a protest is stupid, and it is a different thing to engage in the transportation of migrants, the second is taking a risk when approaching the most vulnerable to be equally threatened, vulnerable yourself. We have to move the boundaries of political action to be riskier if we want to read them through the laws ... for example, it was dangerous not to go to negotiations; it was difficult to continue with the occupation...

Taking the risk that the students made with the occupation as the political step was significant. They exposed themselves to all institutional regulations that could be used against them and their activities. For example, some of the personal risks they faced were loss of exam sessions, loss of the right to a signature for attendance, loss of a semester, etc. But they were also exposed to the security risk that depended on the decisions and the functioning of the protection regulations. Solidarity understood as assistance or support or as risk-taking, or sharing responsibility proves to be an unavoidable part of creating a community based on the principles of acceptance and commitment were also fundamental for the affective politics as politics of care.

The dialogue is another aspect of the intersubjective experience I want to address related to the political processes that defined the "Autonomous zone" community. This aspect mainly refers to the ongoing deliberation inside the plenum sessions and other informal communication among students. Thus, I want to tackle two parts of the dialogue, the first as a political tool and the other as the intersubjective potential for social and individual transformation.

For students, the dialogue in the Plenum was inseparable from the horizontal structure of the movement and the principle of equality. This is the primary condition for enabling the necessary openness towards the Other expressed through listening and taking the other's position into account. This could be summarized as empathy which students also note as important quality and condition of/for dialogue.

BG: Dialogue is possible only among equals. It can't be among equals and more equal. Then you have negotiations in the classical sense, classic diplomatic discussion. The dialogue should be part of the community that encourages it; there is no dialogue in negotiations. 
BR: (pause) Without empathy, there is no dialogue. (pause) Compassion is not for its emotional aspect but as intellectual processing, the whole package, to enable yourself for empathy.

Students make a difference in dialogue and debate. They differentiate the dialogue through the capacity to understand the other, to empathize. Moreover, they consider dialogue to be the necessary condition for democracy processes as well. Dialogue and debate were both used as political tools for choosing different strategies for accomplishing different political aims. For example, the two main political strategies the students used were the institutionalist approach (filing appeals, requests, accepting meetings and negotiations) and the more radical approach (protests, occupation, etc.) Those approaches were debated and decided as part of the plenum sessions and were the lines that empowered the students' tactics and made the plenum body more vulnerable to ideological differences and outside influences.

SB: I can share something from my field of studies; in peace theory, there is a distinction between dialogue and debate, where debate is when a particular claim is placed forward, and dialogue is understanding other's share. In that context, the peaceful transformation of society is essential. I value dialogue as an important part of the exchange of arguments different from debate; they value more deliberation as a concept. Since the debate is positive and discussion of opinions, but it is self-centered and, in its essence, is the devaluation of the arguments of the others. While in dialogue, it is the opposite, it is important to understand the position and arguments. In the context of the Student Plenum, I would say that there is a place for debate and dialogue, and when there is extreme opposition, extreme differences, there is more place for debate than less for dialogue.

$R$ : What is necessary for dialogue to happen?

LL:Itisprobablyrelated tothehorizontality, with thepeoplebeingincluded...When the Plenum started to expand, there were joint gatherings, socare in the horizontal organization and consideration for others is what makes dialogue possible.

TP: Yes, it is the primary condition for functioning, not just as a horizontal organization but also as a society. If there is no dialogue, there is no understanding, and if there is no understanding, there is no tolerance, and if there is no tolerance, there is tension, and if there is tension, there is violence. So it is not a strategic position; it is a spontaneous part of the democratic process.

The emancipating role of the dialogue could be seen through the emerging opportunities for the community based on the principles of solidarity, equality, and difference. It bears the potential and the strength for making decisions and redefining students' position in the social and political field and personal empowerment and growth. Therefore, 
it serves as the transformative potential of the melancholic experience and marginalized position.

BR:...but in essence, if I enter into dialogue, I would prefer that the conversation gets the best qualities from both sides of the argument. To make some shift towards the ideas and concessions and at the end this not to hurt much... It was interesting. I could say that I now have richer experience thanks to these dialogues we had. Since before I never entered into dialogue, I always considered that I should tell what I think if I feel invited and it is to the other to think for themselves. Now we managed to enter into the feedback of dialogue and exchange of symbols, even symbolically...I can say that it is an exciting experience, all that, to be able to talk and to be able to get closer to different horizons and merge them, as Gadamer would say, but we can't understand each other completely. I believe that we can't understand each other. But again, those words, those categories that the language enables us with, are good intermediation.

BG: Yes, it is the product of dialogue, acceptance of the community, the community's openness towards multiethnicity, multilingualism, various sexuali$t y$, and it was the product of good dialogue.

VR: Making more mature decisions, development of the sense of belonging and comfort, being accepted from the others that participate in the dialogue....it has some thoughtfulness some wisdom, you have opportunity to listen to incorporate more aspects, to make a synthesis, to strengthen a community, since at the end a community, what is a community today is its spirit. I've experienced situations and processes in which people were heard, their opinion was not always accepted, but they were accepted, and it was ok to be there, ok that they've said something and no one is going to expel them or talk behind their back for what they've said. So that is the basis on which we can develop progressive changes.

The most powerful aspect of the intersubjective experience of dialogue is what happens "between" - according to Buber, the sphere of dialogue that is co-created "between" bears the transformative potential. This potential is possible within the realm of the social. It is again not individual experience but shared and embodied reality and experience.

\section{Conclusion}

The conceptualization of experiences from the "Autonomous Zone" opens up the possibilities for political imagination. The "Autonomous Zone" has a specific meaning that is not exhausted solely with the political demands of the movement but is a process of creating a new community that reevaluates the essential practices of the functioning 
of the University and society. The new position in the political and social field was conquered through the organized movement and the established community of the "Autonomous zone." This transformation resulted from the specific affective politics of the "Autonomous zone" embodied and enacted through the affective experiences, intimacy, dialogue, responsibility, and solidarity where students felt empowered to take political action. Establishing the "Autonomous zone" interrupts the existing reality spatially and temporally and symbolically shows a new one.

Personal experiences during the "Autonomous zone" are essential for the political processes in which they participate and related to overcoming the melancholic position of the students. The analysis of the data from the survey shows that their embodied and enacted affective experiences reflect both internal dynamics but also the social dynamics and experiences as bearers of the possibilities for change, that is, the transformation of the melancholic experience.

The specific conditions and way of relating through intersubjective and interaffective experiences are also grounded and enabled by the horizontal organization and the principles of inclusiveness, equity in decision-making, and responsibility. These are the critical conditions for overcoming the melancholy position of powerlessness, submission, and isolation, which empower students and influence their transformation and social status.

The quality of the community students created based on shared values enabled achieving a certain shared political goal. The experiences of the students from the "Autonomous Zone" are taken as an example for creating a new political community that emerges from the social movement, which is a step forward in the realization of a vision of a social change that is not based on the distribution of power relations, but the allocation of responsibility and care. Although the "Autonomous Zone" had primarily a strategic political goal of strengthening the pressure on the authorities and defending the autonomy of the University, the way it worked could serve as an example that draws the basic outlines of one a small political community on politics of care. 


\section{References}

Ahmed, Sara. The Cultural Politics of Emotion. Edinburgh: Edinburgh University Press, 2004.

Blazheva, Ana. „Emotions and the Political: The Transformative Potential of Melancholy“. Identities: Journal for Politics, Gender and Culture. Volume 13, 2016/17. Skopje: Institute of Social Sciences and Humanities - Skopje, 2017.

Cheng, Anne Anlin. The Melancholy of Race: Psychoanalysis, Assimilation and Hidden Greif. Oxford: Oxford University Press, 2000.

Durt, Christoph, Fuchs, Thomas, Tewes, Christian. Ed. Embodiment, Enaction, and Culture Investigating the Constitution of the Shared World. The MIT Press Cambridge, Massachusetts, London, 2017.

Eng, David L., Kazanjian, David. Loss: The Politics of Mourning. Berkeley: University of California Press, 2003.

Federici, Silvia. Caliban and the Witch: Woman, the Body and Primitive Accumulation. Brooklyn NY: Autonomedia, 2004.

Federici, Silvia. Revolution Point Zero: Household Reproduction and Feminist Struggle. Verlag: PM Press, Common Notions, 2012.

Federici, Silvia. Women, Reproduction, and the Construction of Commons. Museum of Arts and Design (MAD), https://www.voutube.com/watch?v=zBBbVpbmRP0, пристапено на: 30.5.2018.

Feld, Alina N. Melancholy and the Otherness of God: A Study of the Hermeneutics of Depression. Plymouth: Lexington Books, 2011.

Freud, Sigmund. „Mourning and Melancholia“. The Standard Edition of the Complete Psychological Works of Sigmund Freud, Volume XIV (1914-1916): On the History of the Psycho-Analytic Movement, Papers on Metapsychology and Other Works, by Freud Sigmund, 1917, 237-258, London : The Hogarth press : The Institute of Psycho-Analysis, 1957. 
Frijda, N. H. The Emotions, Cambridge, UK and New York: Cambridge University Press, 1987.

Jasper, James M. „Cultural Approaches in the Sociology of Social Movements“. Handbook of Social Movements Across Disciplines, by Klandermans, Bert, Roggeband, Conny. NY: Springer, 2010.

Klandermans, Bert, Roggeband, Conny. Handbook of Social Movements Across Disciplines. New York: Springer, 2010.

Klein, Melanie. „A Contribution to the Psychogenesis of Manic-Depressive States“. The International Journal of Psychoanalysis 16, 1935, 145-174.

Klein, Melanie. „Mourning and its relation to manic-depressive states“. The International Journal of Psychoanalysis 21, 1940,125-153.

Klibansky, Raymond, Panofsky, Erwin, Saxl, Fritz. Saturn and Melancholy: Studies in the History of Natural Philosophy, Religion, and Art. New York: Basic Books, 1964.

Koopmans, Ruud. „Protest in Time and Space: The Evolution of Waves of Contention“. The Blackwell Companion to Social Movements, edited by David A. Snow, Sarah A. Soule, Hanspeter Kriesi. Blackwell Publishing Ltd., 2004.

Kristeva Julia, The Black Sun: Depression and Melancholia, Columbia University Press, New York, 1989, 1-300.

Levitsky, Steven, Way, Lucan. „The Rise of Competitive Authoritarianism“. Journal of Democracy 13, no. 2 (2002), 51-65, doi:10.1353/jod.2002.0026.

Lipsky, Michael. „Protest as a Political Resource“. American Political Science Review 62, 1968, 1144-1158.

Madison, D. Soyini. Critical Ethnography: Method, Ethics and Performance. Thousend Oaks: Sage Publications, 2005.

McAdam, Doug, Tarrow, Sidney, Tilly, Charles. Dynamics of Contention. New York: Cambridge University Press, 2001.

Meyer, Christian, Streeck, Jürgen, Jordan, J. Scott. Intercorporeality: Emerging Socialities in Interaction. Oxford University Press, 2017. 


\section{EthnoAnthropoZoom}

Meyer, David S., Lupo, Lindsey. „Assessing the Politics of Protest: Political Science and the Study of Social Movements“. Handbook of Social Movements Across Disciplines, by Klandermans, Bert, Roggeband, Conny. NY: Springer, 2010.

Morris, A. D. „Political Consciousness and Collective Action“. Frontiers in Social Movement Theory, edited by A. D. Morris and C. McClurg Mueller. Binghampton, NY: Vail-Ballou Press, 1992, 351-373.

Mouffe, Chantal. Dimensions of Radical Democracy. Verso, 1992.

Salman, Ton, Assies, Willem. „Anthropology and the Study of Social Movements“. Handbook of Social Movements Across Disciplines, by Klandermans, Bert, Roggeband, Conny. NY: Springer, 2010.

Saukko, Paula. Doing Research in Cultural Studies: An introduction to classical and new methodological approaches. SAGE Publications, 2003.

Schiesari, Juliana. The Gendering of Melancholia: Feminism, Psychoanalysis, and the Symbolics of Loss in Renaissance Literature. Ithaca and London: Cornell University Press, 1992.

Smith, Jackie, Fetner, Tina. „Structural Approaches in the Sociology of Social Movements“. Handbook of Social Movements Across Disciplines, by Klandermans, Bert, Roggeband, Conny. NY: Springer, 2010.

Snow, David A., Soule, Sarah A., Kriesi, Hanspeter. „Mapping the Terrainin“. The Blackwell Companion to Social Movements, edited by David A. Snow, Sarah A. Soule, Hanspeter Kriesi. Blackwell Publishing Ltd., 2004.

Stekelenburg, Jacquelien van, Klandermans, Bert. „Individuals in Movements“. A Social Psychology of Contention, Handbook of Social Movements Across Disciplines, by Klandermans, Bert, Roggeband, Conny. NY: Springer, 2010.

Pensky, Max. Melancholy Dialectics: Walter Benjamin and the Play of Mourning Critical Perspectives On Modern Culture. Amherst: University of Massachusetts Press, 1993.

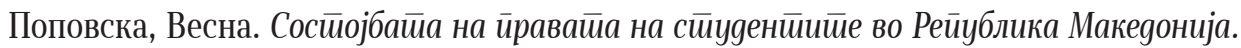
Fridrih Ebert Stiftung, 2010.

Radden, Jennifer. The Nature of Melancholy: From Aristotle to Kristeva. New York: Oxford University Press, 2000. 
Federici, Silvia. Women, Reproduction, and the Construction of Commons. Museum of Arts and Design (MAD), https://www.youtube.com/watch?v=zBBbVpbmRP0, пристапено на: 30.5.2018.

Feld, Alina N. Melancholy and the Otherness of God: A Study of the Hermeneutics of Depression. Plymouth: Lexington Books, 2011.

Freud, Sigmund. „Mourning and Melancholia“. The Standard Edition of the Complete Psychological Works of Sigmund Freud, Volume XIV (1914-1916): On the History of the Psycho-Analytic Movement, Papers on Metapsychology and Other Works, by Freud Sigmund, 1917, 237-258, London : The Hogarth press : The Institute of Psycho-Analysis, 1957.

Frijda, N. H. The Emotions, Cambridge, UK and New York: Cambridge University Press, 1987.

Jasper, James M. „Cultural Approaches in the Sociology of Social Movements“. Handbook of Social Movements Across Disciplines, by Klandermans, Bert, Roggeband, Conny. NY: Springer, 2010.

Klandermans, Bert, Roggeband, Conny. Handbook of Social Movements Across Disciplines. New York: Springer, 2010.

Klein, Melanie. „A Contribution to the Psychogenesis of Manic-Depressive States“. The International Journal of Psychoanalysis 16, 1935, 145-174.

Klein, Melanie. „Mourning and its relation to manic-depressive states“. The International Journal of Psychoanalysis 21, 1940,125-153.

Klibansky, Raymond, Panofsky, Erwin, Saxl, Fritz. Saturn and Melancholy: Studies in the History of Natural Philosophy, Religion, and Art. New York: Basic Books, 1964.

Koopmans, Ruud. „Protest in Time and Space: The Evolution of Waves of Contention“. The Blackwell Companion to Social Movements, edited by David A. Snow, Sarah A. Soule, Hanspeter Kriesi. Blackwell Publishing Ltd., 2004.

Kristeva Julia, The Black Sun: Depression and Melancholia, Columbia University Press, New York, 1989, 1-300.

Levitsky, Steven, Way, Lucan. „The Rise of Competitive Authoritarianism“. Journal of Democracy 13, no. 2 (2002), 51-65, doi:10.1353/jod.2002.0026. 


\section{EthnoAnthropoZoom}

Scott, Marratto. The Intercorporeal Self: Merleau Ponty on Subjectivity. Albany: State University of New York, 2012.

TenHouten, Warren D. A General theory of emotions and social life. Routledge Advances in Sociology. New York: Routledge, 2006.

Веб страница на Универзитет „Св. Кирил и Методиј“ во Скопје. Достапна на: http:// www.ukim.edu.mk/mk content.php?meni=41\&glavno=41, Пристапено на: $20,08,2021$ 
Lipsky, Michael. „Protest as a Political Resource“. American Political Science Review 62, 1968, 1144-1158.

Madison, D. Soyini. Critical Ethnography: Method, Ethics and Performance. Thousend Oaks: Sage Publications, 2005.

McAdam, Doug, Tarrow, Sidney, Tilly, Charles. Dynamics of Contention. New York: Cambridge University Press, 2001.

Meyer, Christian, Streeck, Jürgen, Jordan, J. Scott. Intercorporeality: Emerging Socialities in Interaction. Oxford University Press, 2017.

Meyer, David S., Lupo, Lindsey. „Assessing the Politics of Protest: Political Science and the Study of Social Movements“. Handbook of Social Movements Across Disciplines, by Klandermans, Bert, Roggeband, Conny. NY: Springer, 2010.

Morris, A. D. „Political Consciousness and Collective Action“. Frontiers in Social Movement Theory, edited by A. D. Morris and C. McClurg Mueller. Binghampton, NY: Vail-Ballou Press, 1992, 351-373.

Mouffe, Chantal. Dimensions of Radical Democracy. Verso, 1992.

Salman, Ton, Assies, Willem. „Anthropology and the Study of Social Movements“. Handbook of Social Movements Across Disciplines, by Klandermans, Bert, Roggeband, Conny. NY: Springer, 2010.

Saukko, Paula. Doing Research in Cultural Studies: An introduction to classical and new methodological approaches. SAGE Publications, 2003.

Schiesari, Juliana. The Gendering of Melancholia: Feminism, Psychoanalysis, and the Symbolics of Loss in Renaissance Literature. Ithaca and London: Cornell University Press, 1992.

Smith, Jackie, Fetner, Tina. „Structural Approaches in the Sociology of Social Movements“. Handbook of Social Movements Across Disciplines, by Klandermans, Bert, Roggeband, Conny. NY: Springer, 2010.

Snow, David A., Soule, Sarah A., Kriesi, Hanspeter. „Mapping the Terrainin“. The Blackwell Companion to Social Movements, edited by David A. Snow, Sarah A. Soule, Hanspeter Kriesi. Blackwell Publishing Ltd., 2004. 
EthnoAnthropoZoom 
Stekelenburg, Jacquelien van, Klandermans, Bert. „Individuals in Movements“. A Social Psychology of Contention, Handbook of Social Movements Across Disciplines, by Klandermans, Bert, Roggeband, Conny. NY: Springer, 2010.

Pensky, Max. Melancholy Dialectics: Walter Benjamin and the Play of Mourning Critical Perspectives On Modern Culture. Amherst: University of Massachusetts Press, 1993.

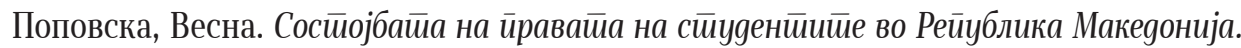
Fridrih Ebert Stiftung, 2010.

Radden, Jennifer. The Nature of Melancholy: From Aristotle to Kristeva. New York: Oxford University Press, 2000.

Scott, Marratto. The Intercorporeal Self: Merleau Ponty on Subjectivity. Albany: State University of New York, 2012.

TenHouten, Warren D. A General theory of emotions and social life. Routledge Advances in Sociology. New York: Routledge, 2006.

Веб страница на Универзитет „Св. Кирил и Методиј“ во Скопје. Достапна на: http:// www.ukim.edu.mk/mk content.php?meni=41\&glavno=41, Пристапено на: $20,08,2021$ 
EthnoAnthropoZoom 